\title{
BENTUK PENYAJIAN TORTOR PADA GONDANG NAPOSO DI KECAMATAN PANGURURAN KABUPATEN SAMOSIR
}

\author{
MARTA SINAGA \\ Prodi Pendidikan Tari
}

\begin{abstract}
This study aims to determine how the form of presentation Tortor in Gondang Naposo in District Pangururan Samosir regency. The theoretical foundation of this research subscribes to the theory that were examined, the theory of presenting the conceptual framework as a translation problem contained therein.This research is a qualitative descriptive study. Data collected by field observations, with video capture, documentation, and conduct interviews with sources, as well as complete the data through research in the area of the District Pangururan Samosir by making artists and local traditional leaders as the population in the research.The results based on the data that has been collected can be seen that Tortor in Gondang Naposo a means to build relationships of young generation and maturation spirit of independence and often the scene of the discovery of a mate who follow the customs of Batak Toba. Gondang naposo event held for two days and started before parnakkok ni mataniari (sunrise). The first day of the three materials are implemented; martonggo raja (inviting parents to participate in the event), ulaon na hohom (only sound gondang) and old mambuat ni gondang (hasuhutan invoke blessings on Mula Jadi Na Bolon). The second day gondangnaposo implementation. In Godang naposo tortor there are seven tortor, namely; tortor mula-mula, tortor somba, tortor mangaliat, tortor sibunga jambu, tortor hatasopisik, tortor simonang-Monang, tortor hasahatan sitio-tio.
\end{abstract}

Keywords: Presentation Form, tortor in Gondang Naposo 


\section{PENDAHULUAN}

Kebudayaan merupakan wujud hasil dari budi daya manusia yang mencakup berbagai pengetahuan manusia, kepercayaan, seni, moral, hukum dan kebiasaan lainnya yang diperoleh manusia sebagai mahluk sosial. Koentjaraningrat

mengatakan bahwa, "Kebudayaan terdiri dari tujuh unsur yakni bahasa, sistem pengetahuan, sistem religi, dan upacara keagamaan, sistem sosial dan organisasi kemasyarakatan, kesenian, sistem mata pencaharian hidup serta sistem teknologi dan peralatan".

Tari adalah gerak-gerak yang disampaikan oleh tubuh sebagai media dan memiliki keindahan. Tari memiliki elemen-elemen dasar yaitu: tema, gerak, iringan tari, tata rias, tata busana, tempat pementasan, setting, lighting, dan properti. Tari merupakan salah satu bagian dari kesenian yang sangat erat hubungannya dengan masyarakat. Dapat disimpulkan bahwa suatu tari bisa dikatakan sebagai ciri dari masyarakat tersebut yang memiliki norma-norma moral dan kesusilaan yang berlaku di wilayahnya seperti diwilayah Kabupaten Samosir.

$$
\text { Kabupaten }
$$

Samosir

merupakan salah satu kabupaten di Provinsi Sumatera Utara yang memilki kesenian yang sangat kaya salah satunya adalah tari (tortor). Penduduk asli yang mendiami kabupaten ini adalah suku Batak Toba. Dalam kehidupan masyarakat Batak Toba, tari (tortor)mempunyai peranan penting dalam aktivitas kehidupan mereka yang berkaitan dengan kehidupan spritual dan sosial kemasyarakatannya. Selain tortor masyarakat Batak Toba juga mempunyai kesenian dibidang musik yang sering disebut gondang atau margondang (memainkan alat musik tradisional Batak Toba). Menurut tradisi adat masyarakat Batak Toba, tortor dan gondang menjadi bagian yang tidak terpisahkan bahkan nama gondang sering dijadikan menjadi nama sebuah tortor dalam setiap kegiatan masayarakat Batak Toba. Adapun kegiatan tersebut diantaranya adalah upacara pernikahan, upacara kematian, memasuki rumah baru dan lainnya. 
Upacara gondang biasanya dilakukan pada waktu pesta bius (pesta wilayah desa) untuk memohon berkah pada Mula Jadi Nabolon, dan pada awal tahun menurut tahun dan bulan Batak, yang disebut sipahasada. Manortor bersama di kalangan Batak tetap berpedoman pada Dalihan Na Tolu dan memakai kain khusus yang sering disebut dengan "ulos". Ulos ini sering dililitkan di kepala atau disandang di bahu. Ulos dan manortor itu merupakan satu ciri khas bagi orang Batak.

Dikalangan muda-mudi Batak terdapat gondang naposo yang khusus diadakan untuk muda-mudi. Gondang naposo merupakan sarana membina hubungan generasi muda dan pematangan jiwa kemandirian. Pada dasarnya acara gondang naposo tidak semata-mata urusan naposo saja. Pada zaman dahulu, acara seperti ini justru diprakarsai oleh orang tua bahkan masalah pembiayaan digalang (dibayar) oleh penduduk setempat. Acara gondang naposo ini dijadikan sebagai sarana mencari jodoh bagi mereka yang sudah cukup umur untuk berumah tangga tetapi belum menemukan pendamping hidup (rokkap). Di kalangan muda-mudi ini juga dikenal beberapa gondang dan tortor yang sering dibawakan dalam acara gondang naposo ini, antara laingondang dan tortor mula-mula, gondang dan somba, gondang dan tortor mangaliat, gondang dan tortor sibunga jambu, gondang dan tortor hatasopisik, gondang dan tortor simonang-monang, serta gondang dan tortor hasahaton sitio-tio.

Bentuk penyajian tortor pada gondang naposo dibagi menjadi tiga bagian, yaitu : 1). Bagian pembukaan (gondang/tortor mula-mula, sombasomba dan tortor mangalliat). 2). Bagian isi sering juga disebut dengan gondang/tortor parsaoran (gondang/tortor sibunga jambu, hatasopisik dan simonang-monang). 3). Bagian ketiga disebut dengan bagian penutup (gondang/tortor hasahatan sitio-tio). Pada gondang naposo, suhut yang akan manortor harus terlebih dahulu maminta gondang mula-mula, baru kemudian maminta gondang lainnya sesuai dengan pilihan dan permintaan mereka. Nama gondang itu adalah 
menurut iramanya, antara lain: gondang sibunga jambu, hatasopisik, simonang-monang termasuk dalam jenis gondang parsaoran. Setelah selesai maminta gondang parsaoran dilanjutkan dengan gondang hasahatan sitio-tio untuk mengakhiri semua tortor dengan pesan, kiranya semua horas-horas, selamat secara jasmani maupun rohani.

Berdasarkan uraian di atas, maka peneliti tertarik mengangkat tari ini menjadi topik penelitian dengan judul: "Bentuk Penyajian Tortor pada Gondang Naposo di

\section{Kecamatan} Pangururan

Kabupaten Samosir”.

\section{Landasan Teori}

Untuk membahas bentuk penyajian tortor pada gondang naposo di Kecamatan Pangururan Kabupaten Samosir, maka penulis menggunakan teori Bentuk Sal Murgianto.

\section{Lokasi dan Waktu Penelitian}

Lokasi penelitian ini dilaksanakan di daerah Pangururan Kabupaten Samosir.

\section{Populasi dan Sampel}

Populasi dan sampel dalam penelitian ini berjumlah tiga orang yaitu narasumber, penari dan pemusik.

\section{Teknik Pengumpulan Data}

Teknik pengumpulan data yang dilakukan adalah sebagai berikut:

1. Observasi

2. Wawancara

3. Dokumentasi

4. Studi kepustakaan

\section{Teknik Analisis Data}

Penulis menganalisis dan menguraikan data-data tersebut dengan menggunakan teknik penelitian kualitatif yaitu sebagai prosedur pemecahan masalah yang diselidiki dengan menggambarakan keadaan objek penelitian pada saat sekarang Kabupaten Samosir.

\section{ISI}

\section{Gambaran Umum}

Letak Geografis Kabupaten Samosir terletak pada $2024^{6}-20$ $25^{`}$ Lintang Utara dan $98021^{`}$ - 990 $55^{`}$ BT. Kabupaten Samosir terletak 
di wilayah dataran tinggi, dengan ketinggian antara $904-2.157$ meter di atas permukaan laut, dengan topografi tanah yang beraneka ragam yaitu datar, landai, miring dan terjal. Struktur tanahnya labil dan berada pada wilayah gempa tektonik dan vulkanik. Kabupaten Samosir tergolong ke dalam daerah beriklim tropis basah dengan suhu berkisar antara $170 \mathrm{C}-290 \mathrm{C}$ dan rata-rata kelembapan udara 85,04 persen.

\section{Jenis Tanah Topografi dan} kontur tanah di Kabupaten Samosir pada umumnya berbukit dan bergelombang. Penggunaan Lahan Kabupaten Samosir memiliki 10 buah sungai yang keseluruhannya bermuara ke Danau Toba. Sebahagian dari sungai tersebut telah dimanfaatkan untuk mengairi lahan sawah seluas 3.987 ha, lahan sawah yang beririgasi setengah teknis $(62,13 \%$ dari luas yang ada). Panjang saluran irigasi di Kabupaten Samosir mencapai $74,77 \mathrm{~km}$, terdiri dari irigasi setengah teknis 70,63 km (21,53 km saluran primer dan 49,10 $\mathrm{km}$ saluran sekunder) dan irigasi sederhana 4,14 km.

\section{Mata Pencaharian}

Dahulunya Masyarakat Batak Toba mata pencahariannya adalah sebagai petani. Para ibu rumah tangga martonun (menenun ulos), namun seiring majunya zaman dan tingkat kebutuhan yang tinggi banyak penduduk Samosirmulai beralih profesi sebagai nelayan kerambah didukung dengan wilayah Kabupaten Samosir yang dikelilingi danau sehingga sangat memungkinkan pekerjaan ini memiliki banyak keuntungan. Namun masih banyak juga sumber daya alam yang bermanfaat dan menjadi mata pencaharian masyarakat setempat yaitu sektor perkebunan, peternakan, perikanan.

Perempuan Batak di wilayah Kabupaten Samosir selain memanfaatkan hasil alam juga mengambangkan industri kerajinan khususnya kerajinan tenun ulos sebagai mata pencaharian sampingan. Kebiasaan tersebut yang membuat perempuan umumnya pintar menenun ulos dikarenakan kegiatan ini diwariskan secara turun temurun. 
Tortor pada Gondang Naposo

\section{Macam-macam Tortor pada} Gondang Naposo

Pada gondang naposo di Kecamatan Pangururan Kabupaten Samosir ada tujuh tortor/tarian yang dibagi menjadi tiga bagian, yaitu:

a. Bagian pembukaan (gondang parjolo)

1) Tortor mula-mula merupakan pembukaan pada acara adat batak. Karena pelaksanaan setiap adat Kebudayaan Batak selalu dimulai dengan acara pembukaan. hal ini dilatar belakangi suatu pemikiran, bahwa pembukaan itu merupakan arahan maksud selanjutnya.

2) Tortor somba-somba merupakan penghormatan sekaligus minta izin kepada raja adat dan para hadirin. Isi pokok sesuatu tortor adalah suatu permohonan, maka yang manortor harus meminta restu kepada para unsur Dalihan Na Tolu dan tokoh adat yang hadir.

3) Tortor mangalliat merupakan suatu pengharapan yang diyakini akan terkabulkan, agar segala yang dimohonkan dapat dimiliki setiap pribadi dan mereka menerimanya dengan suka cita (olop-olop).

b. Bagian isi sering juga disebut dengangondang/tortor

parsaoran

1) Tortor sibunga jambu merupakan tari yang ditarikan oleh kaum wanita yang ingin menunjukkan bahwa mereka sudah menginjak kedewasaan lewat tarian ini, sehingga diharapkan dapat menarik hati lawan jenis yang menyaksikannya. namun seiring perkembangan zaman tortor ini sudah dapat ditarikan oleh muda-mudi atau berpasangan dengan tujuan yang tetap sama, yaitu pendekatan terhadap lawan jenis.

2) Tortor hatasopisikmerupakan media mengungkapkan perasaan cinta, dimana pengungkapan rasa cinta pada tortor hatasopisik disebut husip-husip. 
3) Tortor simonang-monang merupakan pemberi motivasi dan pemberi semangat agar selalu mendapat kemenangan.

c. Bagian ketiga disebut dengan bagian penutup

1) Tortor hasahatan sitio-tio merupakan bagian penutup seluruh tortor. Tortor ini terbagi dua bagian, yang pertama gondang/tortor hasahatan, yang kedua gondang/tortor sitio-tio. Tortor sitio-tio adalah wujud secara simbolik dari segala yang diharapkan, sedangkan tortorhasahatan mengakhiri semua tortor dengan pesan, kiranya semua horas-horas, selamat secara jasmani maupun rohani.

\section{Bentuk Penyajian}

\section{a. Bentuk Bathin}

\section{1). Tema}

Tema menjadi hal yang penting dalam suatu tarian. Berdasarkan dari tema yang dimiliki oleh tari tersebut, maka dapat diketahui apa yang akan disampaikan dari tarian tersebut pada saat dipertunjukkan. Sama halnya dengan tema yang terdapat dalam tortor pada gondang naposo, yaitu Pergaulan.

\section{b. Bentuk Luar}

\section{Gerak}

Gerak dalam tari merupakan suatu hal yang sangat mendasar, dengan gerak dapat tersampaikan isi dari sebuah tarian. Gerak dalam tari dapat tersampaikan isi dari sebuah tarian. Gerak dalam tari dapat dihasilkan melalui unsur tenaga, ruang dan waktu.

\section{Musik Pengiring Tortor Pada Gondang Naposo}

Pada pelaksanaan Gondang Naposo menggunakan Gondang Sabangunan. Gondang Sabangunan pada zaman dahulu digunakan untuk setiap acara yang berhubungan dengan upacara adat maupun upacara religious. Dalam konsep pemikiran masyarakat Batak Toba, kata gondang mempunyai banyak pengertian, diantaranya ialah seperangkat alat musik, sebuah ansambel musik, sebuah komposisi, sebuah repertoar, atau bagian rangkaian upacara. 
Penggunaan kata gondang dalam konteks yang berbeda-beda memberi gambaran tentang konsep berpikir orang Batak mengenai musiknya, membedakan antara upacara pesta adat, upacara bukan adat dan upacara 'agama' serta pengelompokan acara tortor dari unsur-unsur kekerabatannya, jika tidak paham konteks penggunaanya dalam upacara adat kata gondang akan memberi arti yang salah. Pada masyarakat Batak Toba tortor dan musik gondang ibarat koin yang tidak bisa dipisahkan, hal ini sesuai dengan pepatah Batak mengatakan “ didia adong gondang disi adong tortor" yang artinya Dimana terdengar gondang disitulah terdapat tortor. Hal tersebut menyebabkan tortor selalu tampil bersama dengan gondang dan begitu sebaliknya.

Dalam Gondang naposo, orang yang dipercayai untuk membawakan acara dan yang maitta gondang kepada pargonsi adalah raja parhata (pembicara). Susunan nama gondang yang digunakan sebagai musik pengiring dalam tortor pada gondang naposo adalah sebagai berikut: a) Gondang Mula-mula merupakan musik pengiring tortor mula-mula

b) Gondang Somba merupakan musik pengiring tortor somba.

c) Gondang Mangaliat merupakan musik pengiring tortor mangaliat.

d) Gondang Sibunga Jambu merupakan musik pengiring tortor sibunga jambu.

e) Gondang Hata Sopisik merupakan musik pengiring tortor hatasopisik.

f) Gondang Simonang-monang merupakan musik pengiring tortor simonang-monang.

g) Gondang Hasahatan Sitio-tio merupakan musik pengiring tortor hasahatan sitio-tio.

\section{Tata Rias}

Tata rias tortor pada gondang naposo awalnya hanya bersifat natural sebagaimana pemuda-pemudi (naposo) pada kesehariannya. Akan tetapi pada perkembangannya telah menggunakan tata rias untuk panortor perempuan, dan untuk panaortor laki-laki tidak menggunakan make up namun 
terlihat bersih dan rapi untuk mendukung sebuah pertunjukan.

\section{Tata Busana}

Busana yang digunakan pada tortor dalam gondang naposo sesuai gambar di atasadalah sebagai berikut :

a) Busana laki-laki terdiri dari:

\section{(1) Hande-}

hande:menggunakan ulos suri-suri ganjang.

Biasanya disebut saja ulos suri-suri, berhubung coraknya berbentuk sisir memanjang. ulos ini dipergunakan sebagai ampe-ampe/handehande. Ulos ini sering dipakai Pada waktu margondang (memukul gendang) oleh hula-hula menyambut pihak anak boru. Ulos ini juga dapat diberikan sebagai "ulostondi" kepada pengantin.

(2) Singkot: menggunakan ulos sibolang. Ulos ini dapat dipakai untuk keperluan duka cita atau suka cita. Untuk keperluan duka cita biasanya dipilih dari jenis warna hitamnya menonjol, sedang bila dalam acara suka cita dipilih dari warna yang putihnya menonjol.

(3) Tali-tali: menggunanakan bintang maratur. Ulos ini menggambarkan jejeran bintang yang teratur. Jejeran bintang yang teratur didalam ulos ini menunjukkan orang yang patuh, rukun seia dan sekata dalam ikatan kekeluargaan, ulos ini diikatkan di kepala lakilaki.

b) Busana perempun terdiri dari:

(1) Hoba-hoba: menggunakan ulos sibolang. Ulos ini dibalutkan di badan perempuan memutupi bagian dada sampai bawah.

(2) Ampe-ampe: menggunanakan bintang maratur. Ulos ini deselembangkan di bagian 
bahu sebelah kanan

berikut: Gondang Naposo perempuan.

merupakan sarana membina

(3) Ikat

pinggang:

menggunakan sortali gorga

besar yang diliitkan

dipinggang perempuan.

\section{Tempat Pementasan}

Pelaksanaan tortor pada gondang naposo biasanya berlangsung di tempat yang luas. Situasi pelaksanaan itu tentu seperti suasana hiburan di lapangan terbuka (Outdoor). Tortor pada gondang naposo ini tidak dipersiapkan seperti tortor-tortor yang dikemas dengan tempat pementasan yang indah seperti panggung berbentuk U, L, prosenium dan yang lainnya. Tortor dalam gondang naposo sering dilakukan di halaman rumah Batak (dijolo ni jabu)

\section{PENUTUP}

\section{Kesimpulan}

Dari hasil yang telah diuraikan pada pendahuluan hingga pembahasan pada penelitian yang berjudul "Bentuk Penyajian Tortor Pada Gondang Naposo di Kecamatan Pangururran Kabupaten Samosir", maka diperoleh kesimpulan sebagai hubungan generasi muda dan pematangan jiwa kemandirian dan tidak jarang menjadi ajang penemuan jodoh yang mengikuti adat istiadat Batak Toba. Acara gondang naposo dilaksanakan selama dua hari dan dimulai sebelum parnakkok ni mataniari (dimulai sejak pagi hari). Hari pertama dilaksanakan dengan acara martonggo raja (menggundang para orang tua untuk turut berpartisipasi dalam acara tersebut), ulaon na hohom dan mambuat tua ni gondang. Hari kedua pelaksanaan gondang naposo hingga sore hari. Dikalangan muda-mudi ini juga dikenal beberapa gondang dan tortor yang sering dibawakan dalam acara Gondang Naposo ini, antara lain : Gondangdan tortor Mula-mula, Gondang dan tortor Somba, Gondang dan tortor Mangaliat, Gondangdan tortor Sibunga Jambu, Gondang dan tortor Hatasopisik, Gondang dan ortor simonangmonang, serta Gondang dan tortor Hasahaton Sitio-tio.

Bentuk penyajian Tortor pada Gondang Naposo dibagi menjadi tiga 
bagian, yaitu : 1). Bagian pembukaan (Gondang/tortor Mula-mula, Sombasomba dan tortor Mangalliat). 2). Bagian isi sering juga disebut dengan Gondang/tortor parsaoran (Gondang/tortor Sibunga Jambu,Hatasopisik dan Simonangmonang). 3). Bagian ketiga disebut dengan bagian penutup (Gondang/tortor Hasahatan Sitiotio). Pada Gondang Naposo suhut yang akan manortor harus terlebih dahulu maminta Gondang Mulamula, baru kemudian maminta Gondang lainnya sesuai dengan pilihan dan permintaan mereka. Nama Gondang itu adalah menurut iramanya, antara lain: Gondang Sibunga Jambu, Hatasopisik, Siburuk dan lain-lainnya yang termasuk dalam jenis Gondang parsaoran. Setelah selesai maminta Gondang parsaoran dilanjutkan dengan Gondang Hasahatan Sitio-tio untuk mengakhiri semua Tortor dengan pesan, kiranya semua horashoras, selamat secara jasmani maupun rohani.

\section{Saran}

Dari beberapa kesimpulan hasil penelitian ini, diajukan saransaran sebagai berikut:

1. Dengan dilakukannya penelitian ini, penulis berharap kepada masyarakat Batak Toba Kecamatan Pangururan Kabupaten Samosir untuk lebih mencintai kesenian asli dan melestarikan kesenian-kesenian asli suku Batak Toba, agar keberadaannya tidak punah dengan masuknya budayabudaya asing.

2. Setelah dilakukannya penelitian ini, peneliti berharap kepada pemerintah Kecamatan Pangururan Kabupaten Samosir, agar selalu memberikan perhatian terhadap pelestarian kesenian Batak Toba.

3. Pada generasi muda-mudi, khususnya muda-mudi Batak Toba disarankan agar lebih memahami Tortor pada Gondang Naposo serta tetap menjaga keunikannya, ciri khas dan karakteristik yang terdapat pada tortor Batak Toba. 
4. Kepada para seniman, penulis berharap menjaga keutuhan kesenian tradisi Batak Toba dan terus berkarya.

\section{DAFTAR PUSTAKA}

Debora, Ester. 2012. Gondang Sabangunan pada Tortor Sigale-gale di Desa Tomok Kecamatan Simanindo Kabupaten Samosir. Skripsi. Universitas Negeri Medan : Medan.

Fernandus, 2011. Struktur Tortor dalam Upacara Pernikahan Maasyarakat Batak Toba di Kecamatan Siborong-borong. Skripsi. Universitas Negeri Medan : Medan.

Hadeli, 2006. Metode Penelitian Kependidikan. Padang : Quantum Teaching.

Hutasoit, 1979. Komunikasi Batak, Jakarta : Bumi Aksara.

Khaldun, Ibnu, 1985. Kamus Umum Bahasa Indonesia. Jakarta : PT.Rineka Cipta.

Koerantjraningrat, 1990. Pengantar Antropologi. Jakarta : PT.Rineka Cipta.

Koerantjraningrat, 2004. Kebudayaan, Mentalitas dan Pembangunan. Jakarta : Gramedia Pustaka Utama.

Kusumahayati, Hermin, AM.(1990). Makna Tari Dalam Upacara di Indonesia. Pidato Ilmiah 
Pada Dies Natalis,VI, ISI, Yogyakarta.

Murgiyanto, Sal. 1983. Koreografi Pengetahuan Dasar Komposisi Tari. Jakarta : Depertemen Pendidikan dan Kebudayaan.

Narbuko, 2005. Metode Penelitian. Jakarta : Bumi Pustaka.

Nurwani. 2007. Pengetahuan Tari, Diktat Jurusan Sendratasik, FBS Universitas Negeri Medan

Purba, Mauly. 2012. Mengenal Tradisi Gondang dan Tortor Batak Toba. Medan : Universitas Sumatera Utara.

Sibarani, Sadar, 2006, Raja Batak, Jakarta : Partano Bato.

Simanjuntak, BA, 1986, Pemikiran Tentang Batak, Medan

Sugiono, 2008. Metodologi Penelitian Pendidikan. Bandung : Alfabetha.

Sugiono, 2009. Metodologi Penelitian Pendidikan. Bandung : Alfabetha.

Sugiyono, 2009."Metode Penelitian Kuantitatif dan $R \& D ”$. Bandung : TARSITO
Tambunan,Betty. Perkembangan Tortor Batak Toba Tinjauan Terhadap Fungsi dan Bentuk Penyajian. Skripsi. Universitas Negeri Medan : Medan

http://id.wikipedia.org/wiki/tortorbat aktoba

http://tanobatak.wordpress.com/2008 /01/23/gondang-naposo/ http://warungmusikita.blogspot.com/ 2012/10/masyarakat-dan-kesenianbatak-toba.htm http://www.samosirkab.go.id/ http://www.pidiinfo.com/profileinvestasi-daerah/kab-toba$\underline{\text { samosir/profile-kab-toba-samosir }}$ 